Ciechański Erwin, Ciechański Krystian, Szponar Jarosław, Kołątaj Piotr, Szczasny Marcin, Głowniak Andrzej, Szumiło Justyna. Left atrial myxoma with concomitant coronary artery stenosis: comprehensive diagnosis and treatment. Journal of Education, Health and Sport. 2022;12(2):78-83. eISSN 2391-8306. DOI http://dx.doi.org/10.12775/JEHS.2022.12.02.008

https://apcz.umk.pl/JEHS/article/view/JEHS.2022.12.02.008

https://zenodo.org/record/5979545

The journal has had 40 points in Ministry of Education and Science of Poland parametric evaluation. Annex to the announcement of the Minister of Education and Science of December 21, 2021. No. 32343. Has a Journal's Unique Identifier: 201159. Scientific disciplines assigned: Physical Culture Sciences (Field of Medical sciences and health sciences); Health Sciences (Field of Medical Sciences and Health Sciences).

Punkty Ministerialne z 2019 - aktualny rok 40 punktów. Zalącznik do komunikatu Ministra Edukacji i Nauki z dnia 21 grudnia 2021 r. Lp. 32343. Posiada Unikatowy Identyfikator Czasopisma: 201159. Prypise de (c) The Authors 2022;

This article is published with open access at Licensee Open Journal Systems of Nicolaus Copernicus University in Torun, Poland

Open Access. This article is distributed under the terms of the Creative Commons Attribution Noncommercial License which permits any noncommercial use, distribution, and reproduction in any medium, provided the original author (s) and source are credited. This is an open access article licensed under the terms of the Creative Commons Attribution Non commercial license Share alike. The authors declare the publication of this paper.

Received: 26.01.2022. Revised: 26.01.2022. Accepted: 05.02.2022.

\title{
Left atrial myxoma with concomitant coronary artery stenosis: comprehensive diagnosis
} and treatment

Erwin Ciechański ${ }^{1,2}$, Krystian Ciechański ${ }^{2,3}$, Jarosław Szponar ${ }^{5}$, Piotr Kołątaj ${ }^{1}$, Marcin Szczasny ${ }^{1}$, Andrzej Głowniak ${ }^{6}$, Justyna Szumiło ${ }^{7}$

1. Department of Cardiology Stefan Wyszyński Regional Specialist Hospital, Lublin, Poland

2. Department of Toxicology Medical University of Lublin

3. Department of Gastroenerology Stefan Wyszyński Regional Specialist Hospital, Lublin, Poland

4. Department and Clinic of Cardiosurgery Medical University of Lublin

5. Clinical Department of Toxicology and Cardiology, Stefan Wyszyński Regional Specialist Hospital, Lublin, Poland

6. Department and Clinic of Cardiology Medical University of Lublin

7. Chair and Department of Clinical Pathomorphology, Medical University of Lublin.

Correspondance to: Erwin Ciechański, Depatment of Cardiology Stefan Wyszyński Regional Specialist Hospital, Lublin, Poland, phone +48663151918, email: erwciech@gmail.com

Conflict of interest: none declared

Key words: cardiac tumor, myxoma, heart failure, CABG

\begin{abstract}
A 69-year-old patient was admitted to the Department of Cardiology due to an accidental finding on a chest X-ray, enlarged heart outline, accompanied by worsening of heart failure to NYHA II with LVEF, about 30\%. In the X-ray description, an enlargement of the left atrium silhouette with local calcifications. The patient underwent TTE, confirming the presence of a
\end{abstract}


pedunculated tumor of the left atrium attached to the ceiling measuring $3.5 \times 3.5 \times 2.2 \mathrm{~cm}$. Due to the ischemic heart disease manifestation patient uderwent coronarography confirming the presence of single-vessel coronary artery disease with changes in the middle segment of the LAD. Patient was treated with CABG LIMA-LAD surgery and removeal the left atrial tumor. Post operation tissue material prooved the preseance of left atrium myxoma. The postoperative course was uneventful, the patient was discharged home.

A 69-year-old patient was admitted to the Department of Cardiology due to an accidental finding on a chest X-ray, enlarged heart outline, accompanied by worsening of heart failure to NYHA II with LVEF, about 30\%. In the X-ray description, an enlargement of the left atrium silhouette with local calcifications. She had a history of rheumatoid arthritis, long-term arterial hypertension, heart failure with reduced left ventricular ejection fraction in NYHA functional class II. In a clinical study, BP values were 130 / 80 $\mathrm{mmHg}$, HR 70 / min, regular, with underlying features of pulmonary congestion, without pathological heart murmurs. In laboratory studies without significant deviations.

In the ECG examination performed in the Department, abnormal morphology of the $\mathrm{P}$ wave, ST segment depression in leads I, II, V5, V6. (Figure 1). The patient underwent TTE, confirming the presence of a pedunculated tumor of the left atrium attached to the ceiling measuring $3.5 \times 3.5 \times 2.2 \mathrm{~cm}$. (Figure 2). Fixed tumor (without balloting features) normal morphology and function of the mitral valve. As a result of ischemic heart disease and changes in the functional volume of the left atrium, the patient was diagnosed with heart failure (HFrEF), and a coronary angiography was performed, confirming the presence of single-vessel coronary artery disease with changes in the middle segment of the LAD segment 7 (Figure 3). Additionally, rich tumor vascularization from LCA was visualized. (Video 1). A decision was made to perform CABG LIMA-LAD surgery and remove the left atrial tumor. In extracorporeal circulation, LIMA-LAD anastomosis, diameter $2.5 \mathrm{~mm}$, was established, access through the right atrium was opened. A tumor with a thick peduncle was removed from the left atrium together with a part of the left atrium roof. In the pathomorphological examination, the preparation was described as a brown tumor, $3.5 \times 3.5 \times 2.2 \mathrm{~cm}$ in size, with a smooth surface, mottled cross-section, gelatinous, with features of chronic bleeding. In the microscopic image, typical staining of mucous cells with signs of bleeding, positive staining towards CD 34 (Figure 4). The postoperative course was uneventful, the patient was discharged home.

Primary heart tumors occur with the frequency of $0.001 \%$ to $0.030 \%$ in the autopsy material [1], of which about $90 \%$ are benign. Myxoma is the most common among primary heart tumors and is present in more than half of all heart tumors [2]. The tumor can develop in all ventricles of the heart, but in $80 \%$ of cases it comes from the left atrium. Characteristically, they form around the atrial septum (fossa ovalis membranę). They are more common in 
women and often appear in the sixth decade of life. Two basic subtypes have been macroscopically described: solid and villous. They may constitute a component of Carney's syndrome in about $10 \%$ [3]. The most common clinical symptoms of myxoma are: embolism, intracardiac obstruction, arrhythmias, pericardial effusion, symptoms of generalized inflammation (fever, weight loss, increased inflammatory parameters, including IL-6) [4].

Transthoracic echocardiography is the gold standard in the diagnosis of the location and haemodynamic consequences of the heart. TEE may be performed in cases of uncertain location or differentiation between the tumor and the embolic material. The treatment of choice is tumor resection with a healthy tissue margin [5]. In clinical practice, the preoperative examination is a coronary angiography. In the presented case, the study turned out to be justified, showing the presence of coronary heart disease with the necessity of invasive treatment. For this reason, a simultaneous resection of the tumor and the suturing of the LIMA-LAD CABG were performed. Atrial lymphomas have a high risk of recurrence, which is highest up to 4 years after surgery, which is why an outpatient echocardiographic inspection is recommended every 6 months.

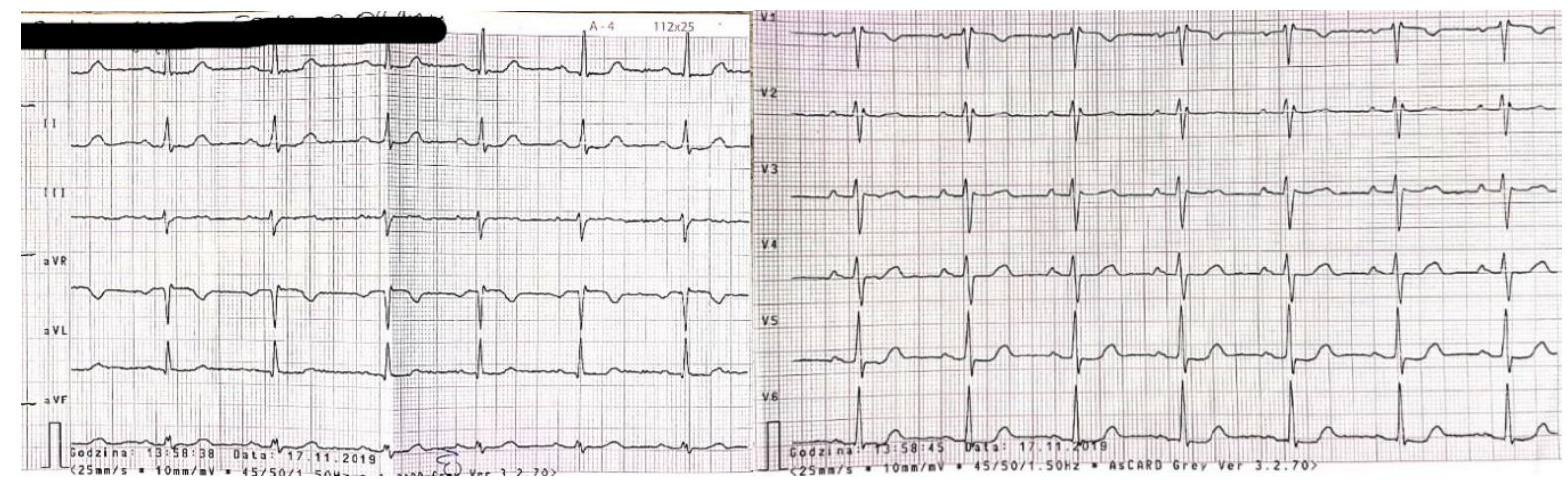

Fig. 1. Electrocadiogram showing abnormal morphology of the $\mathrm{P}$ wave, ST segment depression in leads I, II, V5, V6. 

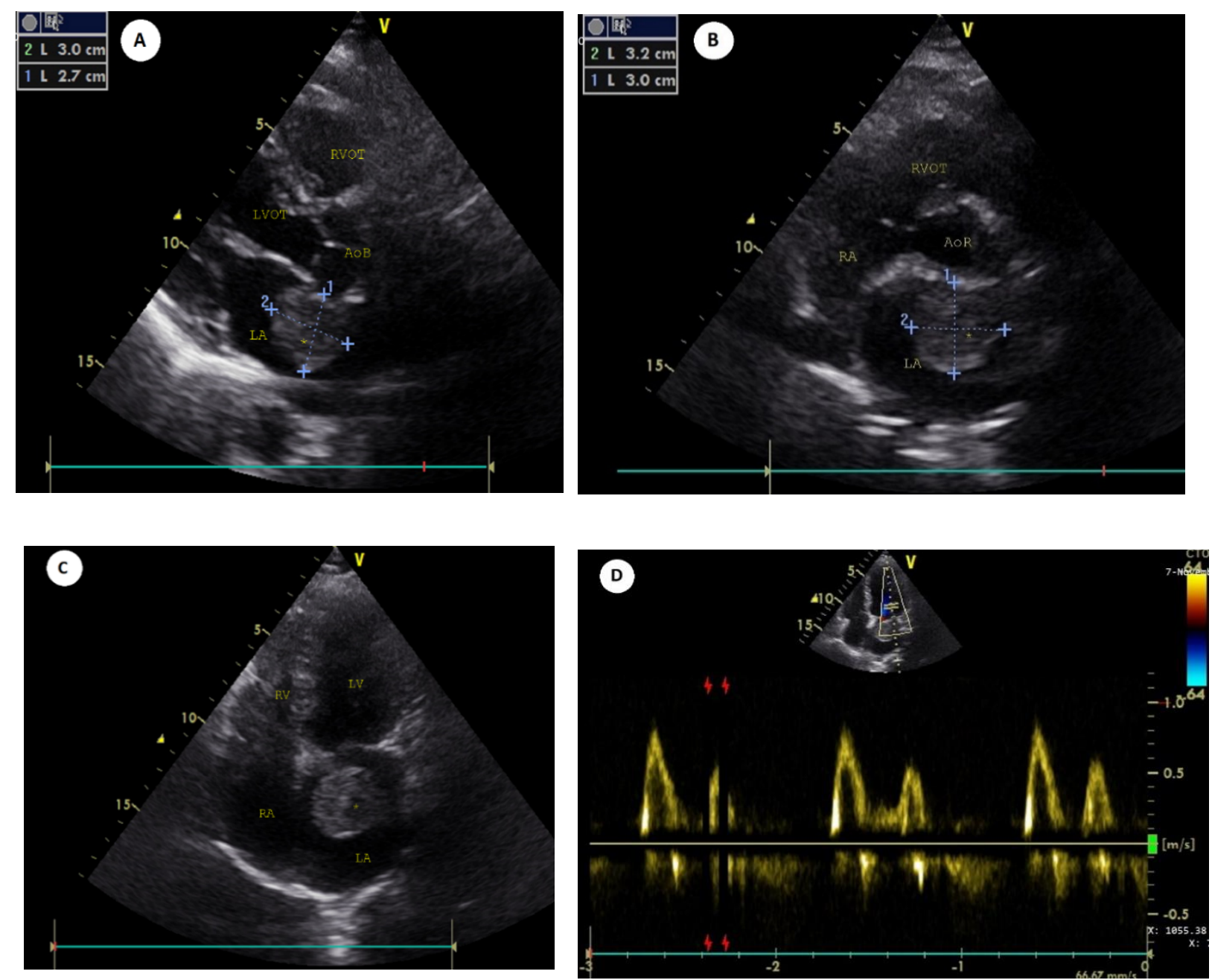

Fig. 2. Transthoracic echocardiography (A), parasternal long axis-view, (B) parasternal shortaxis view, (C) subcostal four chamber view, (D) normal values of mitral influx . Abbreviations: AoR - aortic ring, AoB- aortic bulb, LA - left atrium, LV - left ventricle, LVOT- left ventricular outflow tract, RA - right atrium, RV - right ventricle, RVOT- right ventricular outflow tract, *- tumor. 


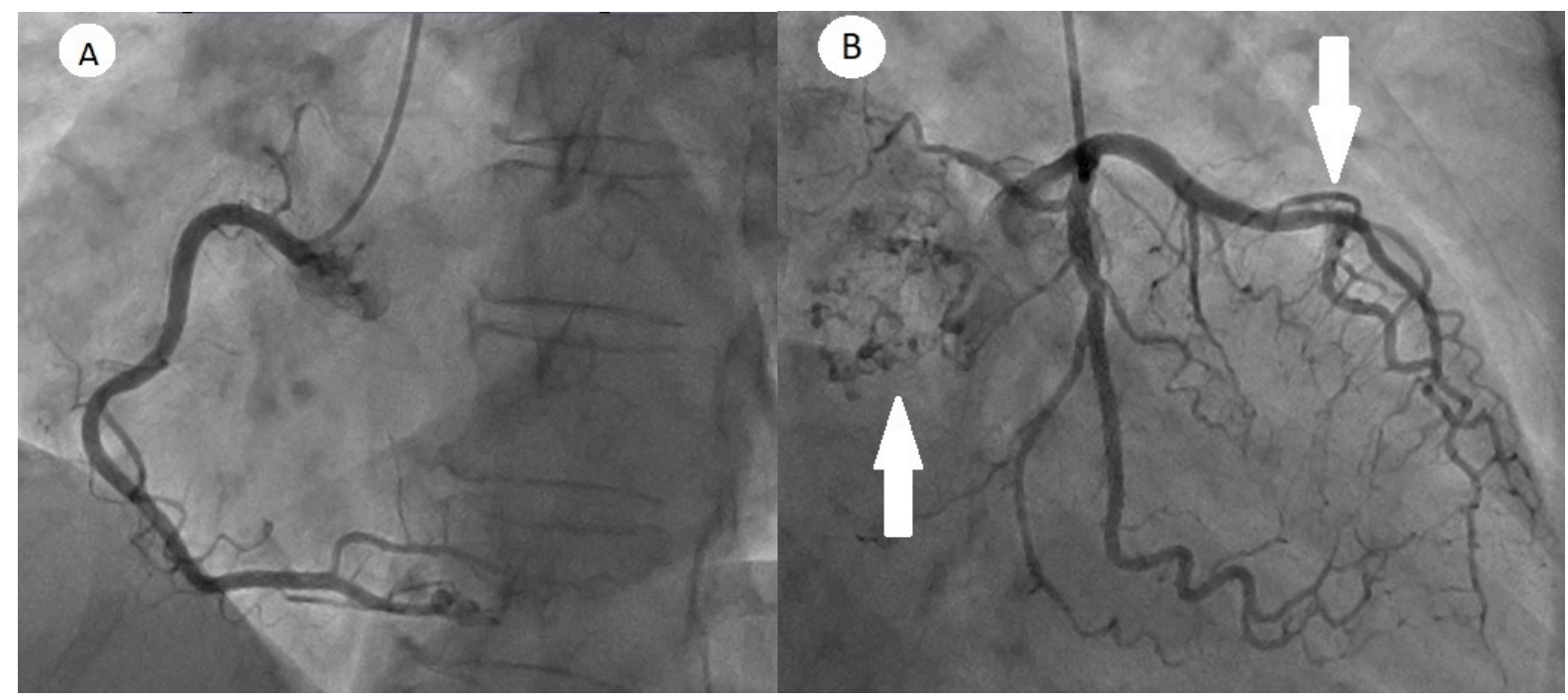

Fig. 3. Coronarography (A) RCA with normal image, (B) LCA with rich tumor neoangiogenesis and calcification, (left arrow), stenosis of LAD in 7 segment (right arrow). LCA- left coronary atery.

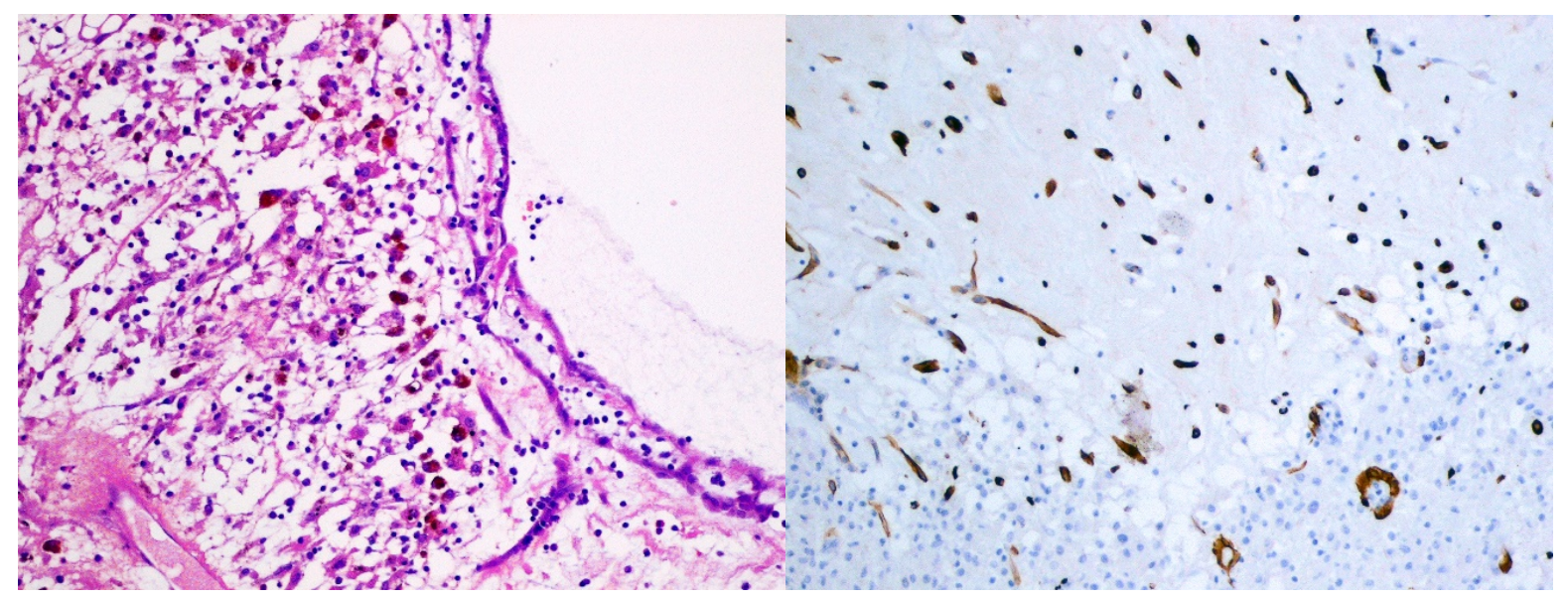

Fig. 4. Histopathology exam (On the left) Myxoma cells with bleeding features, H+E staining. (On the right) Myxoma cells stained positive for CD 34.

Thanks to the Chair and Department of Clinical Pathomorphology, Medical University of Lublin.

Bibliograhy:

1. Nomoto N, Tani T, Konda T, Kim K, Kitai T, Ota M, et al. Primary and metastatic cardiac tumors: echocardiographic diagnosis, treatment and prognosis in a 15-years single center study. J Cardiothorac Surg. 2017 Nov;12(1):103.

2. Ali MU, Finkel J. Atrial Myxoma. N Engl J Med. 2018 Oct;379(16):e26. 
3. Ando T, Goto H, Date K, Okada H, Takeda M, Kasahara K. Recurrence of cardiac myxoma in the right atrium with Carney complex following resection of myxomas in both ventricles. Gen Thorac Cardiovasc Surg. 2019 Oct;67(10):891-3.

4. Strecker T, Rösch J, Weyand M, Agaimy A. Primary and metastatic cardiac tumors: imaging characteristics, surgical treatment, and histopathological spectrum: a 10-yearexperience at a German heart center. Cardiovasc Pathol Off J Soc Cardiovasc Pathol. 2012;21(5):436-43.

5. Centofanti P, Di Rosa E, Deorsola L, Dato GM, Patanè F, La Torre M, et al. Primary cardiac tumors: early and late results of surgical treatment in 91 patients. Ann Thorac Surg. 1999 Oct;68(4):1236-41. 